\section{The Institutional Investor Impact on Stock Prices}

\author{
Elaine Borges 1 \\ ${ }^{1}$ University of Säo Paulo, School of Arts, Sciences and Humanities, \\ Marketing Department, São Paulo, Brazil \\ Roy Martelanc ${ }^{2}$ \\ ${ }^{2}$ University of São Paulo, Faculty of Economics, Administration, Accounting and \\ Actuarial, Department of Administration, São Paulo, Brazil
}

\begin{abstract}
Purpose - This study aims to analyze the impact of mutual funds trading shares together for consecutive periods in the price of these shares.

Design/methodology/approach - Fixed-effects panel regression analyzes were performed to identify the relationship between persistence, which measures how many consecutive periods a particular share was bought or sold by the pool of funds, and the returns of the same stock in the short and medium term.

Findings -Shares that are purchased by the pool of funds persistently have reduced returns, and stocks sold have increased returns in both short and medium term. In addition, the sample that gathered small funds with active strategy, buying and selling small caps, presented the most statistical and economic relevance in all periods.

Originality/value - These results allow us to question the ability of small fund managers to select assets and the timing of their transactions, as well as their contribution as well-informed investors to the equilibrium of capital market prices.
\end{abstract}

Keywords - investment funds; institutional investor; persistence, herd effect; stocks; stock price
Received on

09/18/2017

Approved on

$11 / 30 / 2018$

Responsible editor:

Prof. Dr. Joelson Oliveira

Evaluation process:

Double Blind Review

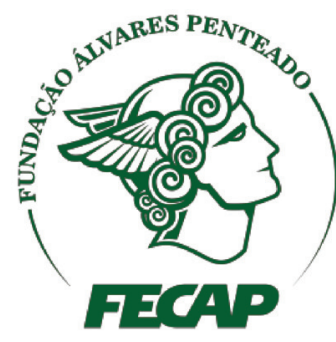

Review of Business Management 


\section{Introdution}

The purpose of this study is to analyze the impact of mutual funds trading stocks together for consecutive periods on the price of these stocks. The tendency of the funds to carry out buy-sell transactions similar to each other, as if one copied the other, was called in the literature institutional herd effect. This effect was positively identified in Brazil and in the world by a series of studies such as Klemkosky (1977), Kraus and Stoll (1972), Friend, Blume and Crockett (1970) and Tariki (2014). The present study investigates the impact of the institutional herd effect of Brazilian funds on stock prices.

There are three possible explanations for the existence of the institutional herd effect. The first is that funds seek to follow the leader, that is, the fund that has managed to get the best results. The second is based on the hypothesis that funds receive the same private information and observe the same financial indicators when choosing stocks, so the herd effect would be a natural consequence of this informational equality. Finally, the third is based on the asymmetry of reputational effects: funds prefer to act in a similar way since being a negative highlight in the industry could have very negative consequences and may not be worth the risk, in which case fund managers would not have incentive to take risk.

One of the consequences of the institutional herd effect that motivates studies directed to it is the distortions of stock prices caused by pressures of supply or demand, consequence of the funds trading. At first, for being well-informed investors, funds would be expected to contribute to bringing stock prices to their equilibrium by buying undervalued shares and selling the overvalued ones, acting in this way as price stabilizers. However, the existence of the institutional herd effect advocates that funds would be price destabilizing, that is, by trading shares, funds would push their prices away from their equilibrium, leading to a price deviation in the short term, followed by a price reversal in the medium term. According to this hypothesis, stocks purchased jointly by funds would have their prices increased in the short term, due to the increased demand generated by funds, and in the medium term prices would suffer a reduction, thus generating an average return. The same would happen with stocks sold by funds, in the short term their prices would suffer a reduction due to supply increase, and in the medium term this reduction would be reversed.

Initially, studies that address the institutional herd effect on stock prices have evaluated their short-term impacts. Wermers (1999) and Sias (2004) studied the impact of American funds trading stocks on the price of these stocks and both found evidence in the short term of price increases of the stocks sold and price decreases of stocks that was bought by funds. However, Bikhchandani, Hirshleifer, and Welch (1992), and Sharfstein and Stein (1990) have identified that the institutional herd effect creates persistence of decision over time, that is, when a fund buys a particular stock in multiple periods other funds mimic their choice more broadly, emphasizing the importance of observing the impact of the institutional herd effect in the medium term and in consecutive periods. Dasgupta, Prat, and Verardo (2011) have taken this feature of the institutional herd effect into account and have created a variable called persistence to record the number of consecutive repetition of stocks purchases and sales by the pool of US funds over time and their impact on both short and medium term prices. In the short term the results have remained, stocks bought (sold) by funds have their prices increased (reduced). The authors, however, found evidence that in the medium term the relationship between persistence and prices is reversed, that is, shares persistently bought by the pool of funds present low prices, and shares sold for consecutive periods present their prices increased in the medium term. This evidence corroborates the destabilizing hypothesis of prices, that funds push equity prices away from their equilibrium, generating a rise (decrease) 
in the price of shares bought (sold) at first, and then a reversal of that trend, contradicting the argument that funds would know how to choose winning shares.

In 2016, the Brazilian investment funds industry reached 3.1 trillion in equity, making it the seventh largest in the world with more than 12 million quota holders. According to the 2015 investment fund industry yearbook, conducted by the Getúlio Vargas Foundation (FGV) and the Brazilian Association of Financial and Capital Market Entities (Anbima), the industry has almost doubled in size in the last 5 years, and this expressive growth has been occurring for at least 20 years. In addition, funds have a significant presence on the São Paulo Stock Exchange (B3), being one of the main groups that trade stocks, since Brazilian people does not yet have the culture to invest directly in the stock exchange, which reinforces the importance of investigating the role of funds in adjusting stock prices in Brazil.

In addition to the expressiveness of the size of the fund industry in the country and its important presence in B3, previous studies such as Borges and Martelanc (2015) identified a higher percentage of funds with ability to generate above-average returns in Brazil compared to the results presented by Fama (2010) in the USA, leading to believe that Brazil has a greater market inefficiency than developed countries, and that the role of funds in the adjustment of stock prices in Brazil could be more preponderant than what was identified in a similar study in the USA. Believing that these scenario differences may be an indication that the impact of funds on share prices here in Brazil is different from that identified in the US, this study is relevant.

In order to study the impact of institutional investor on the stock price, the monthly database for the composition of Brazilian fund's portfolio maintained by Anbima was used; this database is relatively recent in Brazil and therefore not yet studied, since before 2009 funds did not have to disclose their portfolio on specific dates. Fixedeffects panel regression analyzes were performed to identify the relationship between persistence, which measures how many consecutive periods a particular share was bought or sold by the pool of funds, and the returns of the same stock in the short and medium term.

Results differ from those presented in the American study, as expected. Stocks that are purchased by the pool of funds persistently have reduced returns, and stocks sold have increased returns in both the short and medium term. In addition, the sample that gathered small funds with active strategy, trading small caps, presented the most statistical and economic relevance in all periods. These results allow us to question the ability of small fund managers to select assets and the timing of their transactions, as well as their contribution as well-informed investors to the equilibrium of capital market prices.

\section{Theoretical references}

\section{I International Studies}

Some of the earliest published studies with evidence of the institutional herd effect were Klemkosky (1977), Kraus and Stoll (1972) and Friend, Blume and Crockett (1970). Klemkosky (1977) has identified that institutional investors often tended to pre-dominate on one side of the market (buying or selling) for a given stock at any given time, thereby creating an imbalance. The author found evidence of the follow the leader strategy among funds. Kraus and Stoll (1972) aimed to identify the contribution of institutional investors block trades in market efficiency of the stock exchange, and were able to determine the tendency to herd in these institutions.

In the same line of thought, De Bondt and Thaler (1985) also identified the herd effect in investments, the main objective of the authors was to identify if there was an exaggerated reaction on the part of stock investors, and were found consistent evidences of exaggerated reaction and later reversion to returns average. Lakonishok, Shleifer, and Vishny (1992) found evidence of both positive feedback and herding in pension 
funds, particularly trading small caps. Grinblatt, Titman, and Wermers (1995) and Wermers (1997) have documented that the vast majority of funds use packaged strategies or use positive feedback of other managers from previous periods.

Other studies sought to explain the institutional herd effect; Scharfstein and Stein (1990) conclude that asset managers may want to avoid reputational risk that would come from a totally different and original investment strategy. If successful the premium would be great, but if the strategy failed, this manager would be the one to have to explain poor performance. Froot, Scharfstein and Stein (1992) and Hirshleifer, Subrahmanyam and Titman (1994) conclude that fund managers make decisions together because they receive similar private information and refer to the same financial indicators. Bikhchandani, Hirsh-leifer, and Welch (1992) argue that managers can infer the same private information received by well-informed investors through their latest asset purchase and sale transactions, and then negotiate in the same direction as following the leader. Finally, Falkenstein (1996) analyzes that institutional investors may share the same risk aversion in relation to shares with the same characteristics, e.g. liquidity.

With respect to the relationship between the institutional herd effect and the stock price in the short term, Wermers (1999) shows evidence that highly-purchased shares by funds outperform well-sold shares in up to two quarters. Sias (2004) has found evidence that institutional demand is positively correlated to prices in the short term. In the medium term, this relationship is reversed. Dasgupta, Prat and Verardo (2011) have created a variable - called persistence - to measure how many consecutive periods a particular stock is bought or sold by the pool of American funds. They looked at the portfolio of US funds from 1983 to 2004, and found evidence that stocks bought (sold) together by the US funds for consecutive months have their prices decreased (increased) in the medium term. In addition, the authors observed that the effect is stronger with small caps. The explanations suggested by the authors for this phenomenon are: (i) a behavioral bias leads managers to make decisions based on outdated information; (ii) fund managers have no incentive to take risk, because when they are the only ones to present poor performance they may get fired; (iii) fund managers negotiate stocks against insider investors who have superior knowledge of the cash flows of the companies, and are unaware of this fact; (iv) cash flows entering and leaving the funds can define the relationship between fund trading and stock returns. Some papers such as Coval and Stafford (2007) and Frazzini and Lamont (2008) found evidence of a negative correlation between cash inflow and return on equity. However, the authors Dasgupta, Prat and Verardo themselves tested this hypothesis in the 2011 paper and found no relevant evidence.

Some recent international studies have also examined the impact of institutional herd effect, Jiao and Ye (2014) studied the institutional herd effect on hedge funds and their impact on US stock prices. The authors found evidence that mutual funds copy hedge funds, moving the stock price away from equilibrium and generating a subsequent price reversion to average, an important evidence of the destabilizing hypothesis of stock prices generated by the institutional herd effect. Edelen, Ince, and Kadlec (2014) studied the relationship between the institutional investor and abnormal stock returns and concluded that shares purchased by funds tend to be overvalued and are accompanied by abnormal returns in the future, the authors understand that the more likely reason is that funds have preferences for certain stocks characteristics that have performed poorly in the long run. Huang, Wu and Lin (2015) investigated the impact of the institutional herd effect on the relationship between risk and return in the US and concluded that the greater the institutional herd effect, the stronger the explanatory power of the equations that relate risk and return, that is, the more efficient the market is.

In Zeng (2016) data from the American funds portfolio from 1980 to 2010 are analyzed 
and the author concludes that institutional investors overvalue already overvalued stocks and undervalue stocks already undervalued by the market. In addition, the funds have more shares overvalued in the portfolio than undervalued, without making a profit from it. Zeng states that its results contradict the general notion that individual investors generate price noise and say that institutional investors play an important role in the poor valuation of stocks in the capital market; their conclusions are consistent with the destabilizing hypothesis of prices. These recent international studies present evidence that is in line with the results presented in this study.

Lobão and Serra (2002) tested the herd effect on mutual funds in Portugal between 1998 and 2000 and measured an impact four to five times higher than that found in mature markets. In addition, the authors have identified that the herd effect is stronger between funds with lower stock diversity and between mid-market capitalization firms.

Cai, Han, Li, and Li (2017) investigated the institutional herd effect on US government debt securities, and found evidence that the effect in this market is significantly greater than in the stock market. In addition, they have identified that the herding effect causes price distortions when the funds sell the bonds, but not when buy.

\subsection{Empirical Results in Brazil}

Tariki (2014) studied the existence of the herd effect in equity funds in Brazil, and strong evidence of the herd effect was found in the sample. In addition, Tariki has identified that this effect is stronger in stocks with lower market capitalization and in large funds.

Sanches (2013) studied the existence of the herd effect using the measure proposed by Hwang and Salmon (2001), which consists of measuring the stock's beta cross-dispersion according to Fama and French (1993) three factors model. The author found similar results to those in international literature - the evidence suggests the existence of the herd effect in Brazil
- but found no evidence of increased herd effect in periods of crisis, as would be expected.

Borges (2007) studied the anchoring of stock prices in Brazil from 2000 to 2006 and found evidence of the use of the minimum price of the last 52 weeks by the investor for the decision of purchase and sale, the anchorage may have relation with the herd effect. Kutchukian (2010) studied price anchoring as one of the drivers of the herd effect on fund growth in Brazil, and found strong evidence of an institutional herd effect, that is homogeneous between asset and liability funds.

\section{Methodology}

\section{I Data}

In order to study the relationship between stocks trading by the set of Brazilian funds and the price of these stocks, the monthly Anbima database of fund's portfolio composition was used through Economática ${ }^{\oplus}$. In the sample were included all open ended Brazilian mutual funds that have stocks traded in B3 in their portfolio, in the period between September 2009 and February 2016, resulting in 78 months included in the sample. For this study, there is no need to observe funds individually, what matters is the sum of the financial value of each stock in the portfolio of all Brazilian funds in each month.

In order to avoid survival bias, all Brazilian mutual funds, including those that had already been canceled during the analyzed period, were included in the sample. The same treatment was given to all stocks included in the sample. As data were collected by summing up the market value of each share in the portfolio of all Brazilian funds in each month, it is not possible to know in each period how many funds actually had shares in the portfolio, but according to Economática it was considered a total of 39,715 funds (most of the funds already canceled and most with zero stocks in its portfolio) of more than 1,000 different managers, and 413 stocks (many already canceled and not present in fund's portfolios). 
In addition to the main sample that considers all Brazilian funds, the model was also tested in more restricted samples according to certain fund and stock characteristics. Funds with active investment strategy seek to achieve above-average market returns through their ability to select stocks, so it is expected that this group of funds will have a more pronounced effect on the price persistence, since their stock trading are more varied and independent. The size of funds, in terms of assets under management, may also interfere with the quality of their management. In Borges and Martelanc (2015) the performance of Brazilian funds was tested according to the methodology developed by Fama (2010), and evidence was found that small funds would have less ability than larger ones. Therefore, the expectation is that small funds would have a greater impact on stock prices. The size of the stock market capitalization is also a feature known to generate abnormal returns (Fama and French, 1993). In the case of persistence, the hypothesis is that small stocks would have a greater impact on institutional investors herding, since they are generally less liquid shares and therefore with less efficient prices, which could generate greater opportunities for gains. The active funds were selected according to their Anbima classification. Large funds were considered as those with net assets above 100 million reais at the date of their last negotiation, and small funds all others. The criteria for classifying the small caps were the market value of the company being less than 200 million reais.

\subsection{Persistence}

Persistence is the number of consecutive months in which the pool of funds buys or sells a specific stock. The percentage variation in the quantity of a stock $\Delta Q_{i, t}$ in all fund's portfolio will be calculated as the percentage change in the stock's market value in all fund's portfolio, adjusted by the percentage change in the stock's price (adjusted for proceeds): $\Delta Q_{i, t}=\frac{P_{i, t} Q_{i, t}}{P_{i, t-1} Q_{i, t-1}} / \frac{P_{i, t}}{P_{i, t-1}}$. As in Dasgupta, Prat and Verardo (2011), a stock is considered bought (sold) when the percentage variation in the quantity of a share is higher (lower) than the median of that variation considering all stocks in all fund's portfolio, to control for market growth: $\Delta Q_{i, t}>\mu_{\frac{1}{2}} \Delta Q_{j, t}$. Persistence is the number of consecutive months in which a stock is bought (sold) and assumes integer values from +1 to +4 when a stock is bought and from -1 to -4 when it is sold, the maximum persistence value is +4 $(-4)$, i.e. if a stock is bought (sold) for more than 4 consecutive months it will have $+4(-4)$ persistence, shares that have not changed or have not been in fund's portfolio receive a value of 0 . For example, a stock that has a percentage change in its quantity greater than the median at March, April and May 2015 will have a persistence of +3 in May 2015.

\subsection{Econometric Model}

The statistical method applied in this study was panel regression analysis with fixed effects. Fixed effects were chosen, since they control the model for omitted variables that differ between the units (companies), but that are constant over time. In addition, two statistical tests were performed with the data, the Chow Test and the Hausman Test, which indicated the fixed effects as being more adequate for data treatment compared to pooled ordinary least squares (POLS) and random effects. The applied econometric model follows:

$$
\begin{gathered}
R_{i, t+1}=\alpha_{i}+\beta_{1} \operatorname{Pers}_{i, t}+\beta_{2} R_{i, t-48}+\beta_{3} \operatorname{Cap}_{i, t}+\beta_{4} M t B_{i, t}+\beta_{5} \operatorname{Vll}_{i, t}+\beta_{6} P E_{i, t}+ \\
\beta_{7} \operatorname{TnO}_{i, t-1}+D m_{t}+\varepsilon_{i, t}(1)
\end{gathered}
$$


In the model (1), the dependent variable $R_{i, t+1}$ measures the stock return $\mathrm{i}$ in month $\mathrm{t}+1$, that is, in the following month: $R_{i, t+1}=\left(P_{i, t+1}-P_{i, t}\right) / P_{i, t}$. This model was tested with six different specifications for the dependent variable. In addition to the return of the stock in the following month, the model was also applied to the returns of the next three, six, twelve, eighteen and twenty four months, in order to observe the explanatory power of the persistence variable in stock's return in both short and medium term. The return $R_{i, t+3}$ refers to the cumulative return of the following three months: $R_{i, t+3}=\left(P_{i, t+3}-P_{i, t}\right) /_{P_{i, t}}$, the return $R_{i, t+6}$ refers to the cumulative return of the following six months: $R_{i, t+6}=\left(P_{i, t+6}-P_{i, t}\right) /_{P_{i, t}}$, and so on. $\operatorname{Pers}_{i, t}$ is the explanatory variable of interest, which represents the persistence of stock $i$ in the sum of all Brazilian funds in month $\mathrm{t}$.

The other explanatory variables of the model are control variables, which are included for being important variables appointed in literature as stock prices determinants, in order to avoid bias of the omitted variable. The first was the accumulated stock return for the last 4 years $R_{i, t-48}$, since past returns include much of the not captured effects by other variables. The option for a four years period to measure past stock's return, following Dasgupta, Prat and Verardo (2011), was made to facilitate comparison between results, and also a shorter period of time could omit relevant information about the stock, besides giving much weight to recent events, and the moment effect, which occurs in the stock's performance in the past 3 to 12 months, could bias the analyzes. The market capitalization $\mathrm{Cap}_{i, t}$ controls for the size of the company, and the market-to-book index $M t B_{i, t}$, defined by the ratio between market value and book value of the company, was included to capture the growth potential of the company, both factors were pointed out by
Fama and French (1993) as determinants of stock prices. The percentage change in the company's net income for the last quarter $V l l_{i, t}$ identifies the profitability of the company, a factor that directly interferes with the market value of the company, thus, the share price. The $\mathrm{P} / \mathrm{E}$ ratio of the stock $P E_{i, t}$, defined by the ratio between the share price and the company's net earnings per share, indicates the relative position of the company in its sector of activity, which may affect its price. Finally, the stock turnover in the last month $\operatorname{Tn} O_{i, t-1}$, a liquidity indicator defined by the ratio between the number of days in which there was at least one trading with the stock, the number of trades with the stock within the period, and the cash volume transacted with the stock in the same period captures the liquidity of the stock in the stock exchange, a factor that interferes with the stock price. In addition, Falkenstein (1996) analyzes that institutional investors may share the same risk aversion in relation to shares with the same characteristics, e.g. liquidity. The vector $D m_{t}$ corresponds to the 77 dummy variables of month that were inserted in the model to guarantee the robustness of the results.

\section{Results}

Table 1 below compares the explanatory variable persistence coefficients in all 42 tested specifications of the model. The different specifications consider as a dependent variable the returns of one, three, six, twelve, eighteen and twenty four subsequent months, in order to identify the impact of persistence on the stock price in both the short and medium term. The model was also tested with different samples, at first it was tested the set of all funds together, then were selected only large funds, then small funds, active funds, all funds trading only small caps, and finally a combination of some of these restrictions was made. The purpose in this case was to verify whether these fund and stock characteristics influence the impact of persistence on prices. 
Table 1

The persistence impact on stock return.

\begin{tabular}{|c|c|c|c|c|c|c|}
\hline Pers $_{\mathrm{i}, \mathrm{t}}$ & $\mathbf{R}_{\mathrm{i}, \mathrm{t}+1}$ & $\mathbf{R}_{\mathrm{i}, \mathrm{t}+3}$ & $\mathbf{R}_{\mathrm{i}, \mathrm{t}+6}$ & $R_{i, t+12}$ & $\mathbf{R}_{\mathrm{i}, \mathrm{t}+18}$ & $\mathbf{R}_{\mathrm{i}, \mathrm{t}+24}$ \\
\hline All Funds & $-0,00068^{* *}$ & $-0,00173^{* *}$ & $-0,00250^{* *}$ & $-0,00225$ & $-0,00154$ & $-0,00072$ \\
\hline Active Funds & $-0,00096^{* * *}$ & $-0,00196^{* * *}$ & $-0,00357^{* * *}$ & $-0,00238^{*}$ & $-0,00290$ & 0,00193 \\
\hline Large Funds & 0,00163 & $-0,00016$ & $-0,000091$ & 0,00024 & $-0,000026$ & 0,00167 \\
\hline Small Funds & $-0,00104^{* * *}$ & $-0,00178^{* * *}$ & $-0,00207^{* *}$ & $-0,00404^{* * *}$ & $-0,00352^{*}$ & $-0,00044$ \\
\hline Small Caps & $-0,00158^{* *}$ & $-0,00289^{* *}$ & $-0,00314^{*}$ & 0,00038 & $-0,00253$ & 0,00016 \\
\hline Small and Active Funds & $-0,00093^{* * *}$ & $-0,00198^{* * *}$ & $-0,00354^{* * *}$ & $-0,00251^{*}$ & $-0,00305$ & 0,00142 \\
\hline $\begin{array}{l}\text { Small and Active trading } \\
\text { Small Caps }\end{array}$ & $-0,00382^{* * *}$ & $-0,00792^{* * *}$ & $-0,01212^{* * *}$ & $-0,01130^{* *}$ & $-0,02852^{* * *}$ & $-0,00238$ \\
\hline
\end{tabular}

* at $10 \%$ of statistical significance

** at $5 \%$ of statistical significance

*** at $1 \%$ of statistical significance

Results show that persistence presents statistical significance in the short term (from one to six months) in all samples, with the only exception of large funds. In the medium term (from twelve to twenty four months) some samples lose statistical significance. Active funds continue to present statistical evidence of persistence impact in the returns up to 12 months, small funds extend that influence to 18 months, and the sample restricted to small funds with active strategy trading small caps evidences the highest statistical and economic significance for all periods up to 18 months. For the twenty-four months period no persistence effect on the stock price was identified.

In addition, it is possible to observe that the sign of the persistence coefficient is negative in all cases, that is, shares purchased by the pool of funds for consecutive periods have their returns reduced, and shares sold have their returns increased. The coefficients are larger for the sample that pools small active funds trading small caps.

These results differ from the American studies in the short term, in the US there is evidence that persistence has a positive effect on returns up to 6 months, i.e. shares bought (sold) by the pool of US funds for consecutive periods show increase (decrease) returns in the short term. In the medium term, the American studies show a reversal of this trend, the returns of bought stocks fall and of sold ones rise. In Brazil, this inverse effect occurs from the very first month, stocks bought by Brazilian funds for consecutive periods have reduced returns, and the ones sold have increased returns, both in the short and medium term.

In Table 2 it is possible to observe the coefficients and statistics of persistence as well as all the other variables, except for the 77 time dummies, for the sample that gathers all Brazilian funds and all stocks. 
Table 2

The persistence impact considering all Brazilian funds on stock return.

\begin{tabular}{|c|c|c|c|c|c|c|}
\hline & $\mathbf{R}_{\mathrm{i}, \mathrm{t}+1}$ & $\mathbf{R}_{\mathrm{i}, \mathrm{t}+3}$ & $\mathbf{R}_{\mathrm{i}, \mathrm{t}+6}$ & $\mathbf{R}_{\mathrm{i}, \mathrm{t+12}}$ & $\mathbf{R}_{\mathrm{i}, \mathrm{t}+18}$ & $\mathbf{R}_{\mathrm{i}, \mathrm{t}+24}$ \\
\hline Pers $_{i, t}$ & $-0,00068^{* *}$ & $-0,00173^{* *}$ & $-0,00250^{* *}$ & $-0,00225$ & $-0,00154$ & $-0,00072$ \\
\hline $\mathbf{R}_{\mathrm{i}, \mathrm{t}-48: \mathrm{t}}$ & $0,02263^{* * *}$ & $0,02320^{* * *}$ & $0,01202^{* *}$ & $-0,03985^{* * *}$ & $-0,05958^{* * *}$ & $-0,16553^{* * *}$ \\
\hline $\operatorname{Cap}_{\mathrm{i}, \mathrm{t}}$ & $-0,00000^{* * *}$ & $-0,00000^{* * *}$ & $-0,00000^{* *}$ & $-0,00000^{* *}$ & $-0,00000^{* * *}$ & $-0,00000^{*}$ \\
\hline $\mathrm{MtB}_{\mathrm{i}, \mathrm{t}}$ & $-0,00000^{* * *}$ & $-0,00000^{* * *}$ & $0,00000^{* * *}$ & $0,00002^{* * *}$ & $0,00002^{* * *}$ & $0,00003^{* * *}$ \\
\hline $\mathrm{Vll}_{\mathrm{i}, \mathrm{t}}$ & 0,00000 & 0,00002 & $0,00002^{* *}$ & 0,00000 & $0,00007^{* * *}$ & $-0,00002$ \\
\hline $\mathbf{P e}_{\mathrm{i}, \mathrm{t}}$ & 0,00000 & 0,00000 & 0,00000 & $-0,00000$ & 0,00000 & 0,00000 \\
\hline $\mathrm{TnO}_{\mathrm{i}, \mathrm{t}}$ & $0,01057^{* *}$ & 0,01263 & 0,01503 & 0,02810 & $-0,00518$ & $0,09676^{* *}$ \\
\hline $\mathbf{R}^{2}$ & 0,4659 & 0,3771 & 0,1760 & 0,2669 & 0,1829 & 0,5117 \\
\hline Prob $>$ F & 0,00000 & 0,00000 & 0,00000 & 0,00000 & 0,00000 & 0,00000 \\
\hline
\end{tabular}

* at $10 \%$ of statistical significance

** at $5 \%$ of statistical significance

$* * *$ at $1 \%$ of statistical significance

It can be seen from Table 2 that, considering the set of all funds trading shares together for consecutive periods, the persistence presents statistical and economic relevance in the short term, from one to six months, but not in the medium term, from twelve to twenty-four months. All persistence coefficients are negative, indicating that since the first month stocks bought by funds have reduced returns and the ones sold have increased returns. A stock that in a specific month has a persistence of 2 , indicating that it has been bought by all Brazilian funds in the last two months, will have on average a reduction in its next month's return of $0.136 \%$.
It is worth noting that the difference between the coefficients of the model that uses the subsequent three-month return for the model using the subsequent six-month return is small, of $0.08 \%$, which shows that after the first three months the impact of trading shares by funds continues, but loses its strength.

Table 3 shows the coefficients and statistics of all the explanatory variables of the model specification with the most relevant results for the study, which brings together small funds with active strategy trading small caps.

Table 3

The persistence impact of small active funds trading small caps on the stock return.

\begin{tabular}{lcccccc}
\hline & $\mathbf{R}_{\mathrm{i}, \mathrm{t}+1}$ & $\mathbf{R}_{\mathrm{i}, \mathrm{t}+3}$ & $\mathbf{R}_{\mathrm{i}, \mathrm{t}+6}$ & $\mathbf{R}_{\mathrm{i}, \mathrm{t}+12}$ & $\mathbf{R}_{\mathrm{i}, \mathrm{t}+18}$ & $\mathbf{R}_{\mathrm{i}, \mathrm{t}+24}$ \\
\hline $\mathbf{P e r s}_{\mathrm{i}, \mathrm{t}}$ & $-0,00382^{* * *}$ & $-0,00792^{* * *}$ & $-0,01212^{* * *}$ & $-0,01130^{* *}$ & $-0,02852^{* * *}$ & $-0,00238$ \\
\hline $\mathbf{R}_{\mathrm{i}, \mathrm{t}-48: \mathrm{t}}$ & $0,03552^{* * *}$ & $0,03417^{* * *}$ & $0,01696^{*}$ & $-0,04638^{* *}$ & $-0,03400^{*}$ & $-0,15745^{* * *}$ \\
\hline $\mathbf{C a p}_{\mathrm{i}, \mathrm{t}}$ & $0,00023^{* * *}$ & $0,00053^{* * *}$ & $0,00077^{* * *}$ & $0,00115^{* * *}$ & $0,00044^{*}$ & $0,00188^{* * *}$ \\
\hline $\mathbf{M t B}_{\mathrm{i}, \mathrm{t}}$ & $-0,00024$ & 0,00062 & 0,00052 & 0,00162 & 0,00124 & 0,00157 \\
\hline $\mathbf{V l i}_{\mathrm{i}, \mathrm{t}}$ & $-0,00000^{*}$ & $-0,00000^{*}$ & 0,00000 & $0,00001^{* * *}$ & $0,00009^{* * *}$ & $-0,00000$ \\
\hline $\mathbf{P e}_{\mathrm{i}, \mathrm{t}}$ & $0,00000^{* *}$ & 0,00000 & $-0,00000$ & $-0,00000$ & 0,00000 & 0,00000 \\
\hline $\mathbf{T n O}_{\mathrm{i}, \mathrm{t}}$ & $0,44683^{* * *}$ & 0,46771 & $-0,15741$ & $1,69249^{* *}$ & 0,67501 & $2,09684^{*}$ \\
\hline $\mathbf{R}^{2}$ & 0,4156 & 0,4017 & 0,2896 & 0,1349 & 0,1083 & 0,2373 \\
\hline Prob $>\mathbf{F}$ & 0,00000 & 0,00000 & 0,00000 & 0,00000 & 0,00000 & 0,00000 \\
\hline
\end{tabular}

* at $10 \%$ of statistical significance

** at $5 \%$ of statistical significance

*** at $1 \%$ of statistical significance 
It is possible to observe in Table 3 that in the model specification that has as a dependent variable the stock return for next month, stocks with persistence equal to 1 , that is, small caps that were bought by the set of small and active funds in that month, present a coefficient of the explanatory variable persistence of $-0.382 \%$, with $1 \%$ of statistical significance. This means that, on average, small caps bought by small active funds in a given month will show an average reduction in their next-month return of $-0.382 \%$. In the same scenario, small caps that have persistence equal to 4 , that is, that have been bought by the pool of small active funds in the past four consecutive months or more, will have this effect multiplied by 4 . Thus, on average, its return from the next month will decrease by $1.528 \%$, in just one month, an important result, given the interest rates practiced in our market. In Graph 1, presented below, we can observe the average effect of the variable persistence assuming values of -4 to 4 in the stock's returns for subsequent periods:

The following are the Tables 4 to 7 with the coefficients and statistics of all the variables included in the other specifications of the model.

Table 4

Persistence impact of active funds on stock return.

\begin{tabular}{lcccccc}
\hline & $\mathbf{R}_{\mathrm{i}, \mathrm{t+1}}$ & $\mathbf{R}_{\mathrm{i},++3}$ & $\mathbf{R}_{\mathrm{i}, \mathrm{t+6}}$ & $\mathbf{R}_{\mathrm{i}, \mathrm{t+12}}$ & $\mathbf{R}_{\mathrm{i}, \mathrm{t+18}}$ & $\mathbf{R}_{\mathrm{i}, \mathrm{t}+24}$ \\
\hline $\mathbf{P e r s}_{\mathrm{i}, \mathrm{t}}$ & $-0,00096^{* * *}$ & $-0,00196^{* * *}$ & $-0,00357^{* * *}$ & $-0,00238^{*}$ & $-0,00290$ & 0,00193 \\
\hline $\mathbf{R}_{\mathrm{i},-48: \mathrm{t}}$ & $0,02264^{* * *}$ & $0,02332^{* * *}$ & $0,01207^{* *}$ & $-0,03981^{* * *}$ & $-0,05954^{* * *}$ & $-0,16553^{* * *}$ \\
\hline $\mathbf{C a p}_{\mathrm{i}, \mathrm{t}}$ & $-0,00000^{* * *}$ & $-0,00000^{* * *}$ & $-0,00000^{* *}$ & $-0,00000^{* *}$ & $-0,00000^{* * *}$ & $-0,00000^{*}$ \\
\hline $\mathbf{M t B}_{\mathrm{i}, \mathrm{t}}$ & $-0,00000^{* * *}$ & $-0,00000^{* * *}$ & $0,00000^{* * *}$ & $0,00001^{* * *}$ & $0,00002^{* * *}$ & $0,00003^{* * *}$ \\
\hline $\mathbf{V l i}_{\mathrm{i}, \mathrm{t}}$ & 0,00000 & 0,00002 & $0,00002^{* *}$ & 0,00003 & $0,00007^{* * *}$ & $-0,00002$ \\
\hline $\mathbf{P e}_{\mathrm{i}, \mathrm{t}}$ & 0,00000 & 0,00000 & 0,00000 & $-0,00000$ & 0,00000 & 0,00000 \\
\hline $\mathbf{T n O}_{\mathrm{i}, \mathrm{t}}$ & $0,01059^{* *}$ & 0,01265 & 0,01511 & 0,02812 & $-0,00509$ & $0,09661^{* *}$ \\
\hline
\end{tabular}

* at $10 \%$ of statistical significance

** at $5 \%$ of statistical significance

$* * *$ at $1 \%$ of statistical significance

Table 5

Persistence impact of small funds on stock return.

\begin{tabular}{|c|c|c|c|c|c|c|}
\hline & $\mathbf{R}_{\mathrm{i}, \mathrm{t}+1}$ & $\mathbf{R}_{\mathrm{i}, \mathrm{t}+3}$ & $\mathbf{R}_{\mathrm{i}, \mathrm{t}+6}$ & $\mathbf{R}_{\mathrm{i}, \mathrm{t}+12}$ & $\mathbf{R}_{\mathrm{i}, \mathrm{t}+18}$ & $\mathbf{R}_{\mathrm{i}, \mathrm{t}+24}$ \\
\hline Pers $_{\mathrm{i}, \mathrm{t}}$ & $-0,00104^{* * *}$ & $-0,00178^{* * *}$ & $-0,00207^{* *}$ & $-0,00404^{* * *}$ & $-0,00352^{*}$ & $-0,00044$ \\
\hline $\mathbf{R}_{\mathrm{i}, \mathrm{t}-48: \mathrm{t}}$ & $0,02266^{* * *}$ & $0,02327^{* * *}$ & $0,01210^{* *}$ & $-0,03972^{* * *}$ & $-0,05947^{* * *}$ & $-0,16551^{* * *}$ \\
\hline $\operatorname{Cap}_{\mathrm{i}, \mathrm{t}}$ & $-0,00000^{* * *}$ & $-0,00000^{* * *}$ & $-0,00000^{* *}$ & $-0,00000^{* *}$ & $-0,00000^{* * *}$ & $-0,00000^{*}$ \\
\hline $\mathrm{MtB}_{\mathrm{i}, \mathrm{t}}$ & $-0,00000^{* * *}$ & $-0,00000^{* * *}$ & $0,00000^{* * *}$ & $0,00001^{* * *}$ & $0,00002^{* * *}$ & $0,00003^{* * *}$ \\
\hline $\mathrm{Vll}_{\mathrm{i}, \mathrm{t}}$ & 0,00000 & 0,00002 & $0,00002^{* *}$ & 0,00003 & $0,00007^{* * *}$ & $-0,00002$ \\
\hline $\mathbf{P e}_{\mathrm{i}, \mathrm{t}}$ & 0,00000 & 0,00000 & 0,00000 & $-0,00000$ & 0,00000 & 0,00000 \\
\hline $\mathrm{TnO}_{\mathrm{i}, \mathrm{t}}$ & $0,01059^{* *}$ & 0,01262 & 0,01500 & 0,02818 & $-0,00510$ & $0,09675^{* *}$ \\
\hline
\end{tabular}

* at $10 \%$ of statistical significance

** at $5 \%$ of statistical significance

*** at $1 \%$ of statistical significance 
Table 6

Persistence impact of all funds trading small caps on stock return.

\begin{tabular}{lcccccc}
\hline & $\mathbf{R}_{\mathrm{i}, \mathrm{t}+1}$ & $\mathbf{R}_{\mathrm{i}, \mathrm{t}+3}$ & $\mathbf{R}_{\mathrm{i}, \mathrm{t+6}}$ & $\mathbf{R}_{\mathrm{i}, \mathrm{t+12}}$ & $\mathbf{R}_{\mathrm{i}, \mathrm{t+18}}$ & $\mathbf{R}_{\mathrm{i}, \mathrm{t}+24}$ \\
\hline $\mathbf{P e r s}_{\mathrm{i}, \mathrm{t}}$ & $-0,00158^{* *}$ & $-0,00289^{* *}$ & $-0,00314^{*}$ & 0,00038 & $-0,00253$ & 0,00016 \\
\hline $\mathbf{R}_{\mathrm{i}, \mathrm{t}-48: \mathrm{t}}$ & $0,03074^{* * *}$ & $0,02794^{* * *}$ & 0,01177 & $-0,04388^{* * *}$ & $-0,04183^{* * *}$ & $-0,14491^{* * *}$ \\
\hline $\mathbf{C a p}_{\mathrm{i}, \mathrm{t}}$ & $0,00003^{* *}$ & $0,00011^{* * *}$ & $0,00022^{* * *}$ & $0,00031^{* * *}$ & 0,00003 & $0,00047^{* * *}$ \\
\hline $\mathbf{M t B}_{\mathrm{i}, \mathrm{t}}$ & 0,00029 & $0,00132^{* *}$ & $0,00146^{*}$ & $0,00225^{*}$ & 0,00166 & $0,00412^{* *}$ \\
\hline $\mathbf{V l l}_{\mathrm{i}, \mathrm{t}}$ & 0,00000 & 0,00002 & $0,00001^{* *}$ & 0,00003 & $0,00008^{* * *}$ & 0,00000 \\
\hline $\mathbf{P e}_{\mathrm{i}, \mathrm{t}}$ & $0,00000^{* *}$ & 0,00000 & $-0,00000$ & $-0,00000$ & 0,00000 & $-0,00000$ \\
\hline $\mathbf{T n O}_{\mathrm{i}, \mathrm{t}}$ & $0,20458^{* * *}$ & $0,36828^{* * *}$ & 0,24798 & 0,61838 & $0,91777^{* *}$ & $1,22742^{* * *}$ \\
\hline
\end{tabular}

* at $10 \%$ of statistical significance

** at $5 \%$ of statistical significance

*** at $1 \%$ of statistical significance

Table 7

Persistence impact of small active funds on stock return.

\begin{tabular}{lcccccc}
\hline & $\mathbf{R}_{\mathrm{i}, \mathrm{t}+1}$ & $\mathbf{R}_{\mathrm{i}, \mathrm{t}+3}$ & $\mathbf{R}_{\mathrm{i}, \mathrm{t}+6}$ & $\mathbf{R}_{\mathrm{i}, \mathrm{t}+12}$ & $\mathbf{R}_{\mathrm{i}, \mathrm{t}+18}$ & $\mathbf{R}_{\mathrm{i}, \mathrm{t}+24}$ \\
\hline $\mathbf{P e r s}_{\mathrm{i}, \mathrm{t}}$ & $-0,00093^{* * *}$ & $-0,00198^{* * *}$ & $-0,00354^{* * *}$ & $-0,00251^{*}$ & $-0,00305$ & 0,00142 \\
\hline $\mathbf{R}_{\mathrm{i}, \mathrm{t}-48: \mathrm{t}}$ & $0,02264^{* * *}$ & $0,02323^{* * *}$ & $0,01207^{* *}$ & $-0,03981^{* * *}$ & $-0,05954^{* * *}$ & $-0,16553^{* * *}$ \\
\hline $\mathbf{C a p}_{\mathrm{i}, \mathrm{t}}$ & $-0,00000^{* * *}$ & $-0,00000^{* * *}$ & $-0,00000^{* *}$ & $-0,00000^{* *}$ & $-0,00000^{* * *}$ & $-0,00000^{*}$ \\
\hline $\mathbf{M t B}_{\mathrm{i}, \mathrm{t}}$ & $-0,00000^{* * *}$ & $-0,00000^{* * *}$ & $0,00000^{* * *}$ & $0,00001^{* * *}$ & $0,00002^{* * *}$ & $0,00003^{* * *}$ \\
\hline $\mathbf{V l l}_{\mathrm{i}, \mathbf{t}}$ & 0,00000 & 0,00002 & $0,00002^{* *}$ & 0,00003 & $0,00007^{* * *}$ & $-0,00003$ \\
\hline $\mathbf{P e}_{\mathrm{i}, \mathbf{t}}$ & 0,00000 & 0,00000 & 0,00000 & $-0,00000$ & 0,00000 & 0,00000 \\
\hline $\mathbf{T n O}_{\mathrm{i}, \mathbf{t}}$ & $0,01060^{* *}$ & 0,01266 & 0,01512 & 0,02814 & $-0,00507$ & $0,09664^{* *}$ \\
\hline
\end{tabular}

* at $10 \%$ of statistical significance

** at $5 \%$ of statistical significance

$* * *$ at $1 \%$ of statistical significance

\section{I Momentum Effect Robustness Test with Adjusted Past Returns}

Momentum effect, identified by Jegadeesh and Titman (1993) and demonstrated in Carhart (1997), is an important factor that explains stock return. According to this phenomenon, buying stocks with good performance in the last 3 to 12 months and selling stocks with poor performance in the last 3 to 12 months generates abnormal positive returns in the next year. However, this abnormal return dissipates over the next two years. Based on Dasgupta, Prat and Verardo (2011), the last 12 months of the control variable that measures the past four years accumulated return is removed, to avoid the momentum effect to bias persistence results, so if the relevant persistence results continue the momentum effect can be discarded.

Table 8 shows the coefficients of the explanatory variable persistence for the same 42 model specifications estimated in Table 1, with the difference that for the control variable that measures the accumulated return of the last four years, the last twelve months was removed, period in which the moment effect occurs. 
It can be seen in Table 8 that the results have not undergone almost any change with the replacement of the past return control variable. The explanatory variable of interest, persistence, maintained its statistical and economic strength and the coefficients are very close to the previous ones, demonstrating that the identified effect does not concern the momentum effect.

Table 8

Persistence impact on stock return with four-year past return adjusted to remove the momentum effect.

\begin{tabular}{lcccccc} 
Pers $_{\mathrm{i}, \mathrm{t}}$ & $\mathbf{R}_{\mathrm{i}, \mathrm{t}+1}$ & $\mathbf{R}_{\mathrm{i}, \mathrm{t}+3}$ & $\mathbf{R}_{\mathrm{i}, \mathrm{t+6}}$ & $\mathbf{R}_{\mathrm{i}, \mathrm{t}+12}$ & $\mathbf{R}_{\mathrm{i}, \mathrm{t}+18}$ & $\mathbf{R}_{\mathrm{i}, \mathrm{t}+24}$ \\
\hline All Funds & $-0,00077^{* *}$ & $-0,00185^{* *}$ & $-0,00256^{* *}$ & $-0,00186$ & $-0,00067$ & 0,00090 \\
\hline Active Funds & $-0,00096^{* * *}$ & $-0,00207^{* * *}$ & $-0,00378^{* * *}$ & $-0,00242^{*}$ & $-0,00223$ & 0,00305 \\
\hline Large Funds & $-0,00008$ & $-0,00047$ & $-0,00116$ & 0,00039 & 0,00078 & 0,00383 \\
\hline Small Funds & $-0,00103^{* * *}$ & $-0,00182^{* * *}$ & $-0,00212^{* *}$ & $-0,00409^{* *}$ & $-0,00303$ & 0,00031 \\
\hline Small Caps & $-0,00151^{* *}$ & $-0,00262^{*}$ & $-0,00227$ & 0,00001 & $-0,00426$ & $-0,00307$ \\
\hline Small and Active & $-0,00093^{* * *}$ & $-0,00207^{* * *}$ & $-0,00372^{* * *}$ & $-0,00251^{*}$ & $-0,00248$ & 0,00239 \\
\hline $\begin{array}{l}\text { Small and Active trading } \\
\text { Small Caps }\end{array}$ & $-0,00350^{* * *}$ & $-0,00731^{* * *}$ & $-0,01198^{* * *}$ & $-0,01258^{* *}$ & $-0,03198^{* * *}$ & $-0,00642$ \\
\hline
\end{tabular}

* at $10 \%$ of statistical significance

** at $5 \%$ of statistical significance

$* * *$ at $1 \%$ of statistical significance

\section{Conclusions}

The fund industry in Brazil has been booming for over twenty years and is the seventh largest in the world. Given its relevance, it is important to know more deeply the effects of funds on the capital market.

This study sought to investigate the relationship between the stock trade that occur jointly among investment funds, a phenomenon called institutional herd effect, and the prices of these stocks, in the short and medium term.

Some authors, such as Wermers (1999) and Sias (2004), investigated this question and, in the short term, a directly proportional effect between persistence and stock price was identified, that is, stocks purchased by funds had their prices increased in the short term, and the ones sold had their prices reduced. One of the possible explanations for this effect to occur would be increasing demand raising prices.
Other authors have confirmed these results for the short term, and by analyzing the impact of persistence for longer maturities, have identified a price reversal. Dasgupta, Prat, and Verardo (2011) conclude that shares purchased for funds in consecutive periods present negative excess returns in the long run, and the opposite is true for shares sold. Jiao and Ye (2014), Edelen, Ince and Kadlec (2014) and Zeng (2016) studied different samples of funds and periods in the US market, and all found evidence that funds move stock prices away from their equilibrium, generating a long-term price reversal. Zeng (2016) concludes that its results contradict the general notion that individual investors generate price noise and asserts that institutional investors play an important role in the inaccuracy of stock market valuation.

One of the possible consequences for this phenomenon is the destabilizing effect of funds on capital prices on the capital market; according 
to this hypothesis, funds would make nonrational decisions that would, in the first instance, move the stock price away from its equilibrium, generating a posterior return to mean.

In this study, we analyzed all the openended Brazilian funds that have stocks traded in B3 in their portfolio between September 2009 and February 2016. The results obtained were different from those presented in the international literature for the short term, and the same for the medium term. In Brazil, shares purchased by funds for consecutive periods show a fall in returns in the next month, and this effect lasts up to eighteen months. Also, shares sold by the funds present increased returns in the short and medium term.

It is also possible to observe that when the sample was selected by taking into account funds and stocks characteristics known for their effect on prices, persistence coefficients become economically and statistically stronger. When consider in the sample only active funds, i.e. those funds that intend to exceed the average market performance, the effect becomes more significant. The same occurs when considering only small funds.

The decision to consider the size of the fund for the analysis originated from a previous research into the ability of fund managers to generate abnormal returns. In Borges and Martelanc (2015) it was concluded that a percentage of large funds had some degree of skill. In line with these results, large funds did not present any evidence of impact on the prices of stocks traded by them. On the other hand, as expected, small funds showed strong evidence of fund impact on stock prices. Lastly, considering the size of the stock market capitalization, stocks with low market capitalization, small caps, are known to generate abnormal returns. Therefore, panel models with fixed effects were re-estimated considering only small caps, and, according to expectations, the results showed that institutional persistence impact on stock prices is larger and stronger.
Then, in order to investigate the importance extent of these selected characteristics of funds and stocks, the active and small funds were grouped together, and then the active and small funds trading only small caps. In both cases the results presented were also more numerous and stronger, with special emphasis on the last group. When considering small funds with active strategy trading small caps were obtained the most relevant results economically and statistically. Small cap bought by small active funds for consecutive periods had a statistically significant effect on these stocks prices in almost all the analyzed periods. In addition to that, the strength of the impact in case of persistence equal to +3 was $-2.852 \%$ in eighteen months, i.e. a small cap bought by small active funds for the last three consecutive months showed an average reduction of $2.852 \%$ on its return in eighteen months, a relevant impact.

This means that there is evidence that investment funds in Brazil cause, with their herd behavior, a drop in stock returns that they choose to buy together for consecutive periods, both in the short and medium term. One of the possible explanations for this, according to the international literature, is that funds are copied in their decisions to buy or sell stocks, either to follow the leader, either because they take the same indicators into account or to avoid the risk of negative performance when all others perform positively, i.e. in this case the fund manager would have no incentive to take risk.

This behavior can generate a price destabilizing effect, causing the stock price to fall from the first month, and the price of the sold stocks to rise, an effect that can be extended for up to eighteen months. Recalling that the marginal effect is decreasing, that is, the impact is stronger in the first month, and is increasing less and less over the period. Another possible explanation is fund manager's poor stock picking or bad trade timing, especially small funds, since on average the stock purchased has reduced returns in the short and medium term. 
One of the limitations of this study concerns the fact that the fund portfolio composition database is monthly, so transactions of stock purchase and sale made during the month by the funds are not identified in the sample. In addition, there are a number of issues that deserve to be studied from the evidence found in this study. The first one is to investigate which hypothesis would explain the institutional herd effect in the Brazilian context, follow the leader or avoid the risk of being out of the pack. Next, it would be interesting to investigate whether the decisions of fund managers are rational and whether they contribute to asset prices being in equilibrium since they are well-informed investors. Finally, it is interesting to understand the reasons why the results of international studies are different from the Brazilian one in the short term.

\section{References}

Bikhchandani, S., Hirshleifer, D., \& Welch, I. (1992). A Theory of Fads, Fashion, Custom, and Cultural Change as Informational Cascades. Journal of Political Economy, 100(5), 992-1026.

Borges, E. C. (2007). O efeito comportamental na decisão de Investimento: o impacto dos preços máximo e minimo das últimas 52 semanas no volume negociado. Masters Dissertation, Getúlio Vargas Foundation, São Paulo, SP, Brazil.

Borges, E., \& Martelanc, R. (2015). Luck versus skill: an evaluation of mutual funds in Brazil. Revista de Administraçāo, 50(2), 196-207.

Cai, F., Han, S., Li, D., \& Li, Y. (2017). Institutional Herding and Its Price Impact: Evidence from Corporate Bond Market. Journal of Financial Economics. Forthcoming.

Coval, J., \& Stafford, E. (2007). Asset fire sales (and purchases) in equity markets. Journal of Financial Economics, 86(2), 479-512.

Dasgupta, A., Prat, A., \& Verardo, M. (2011). Institutional Trade Persistence and Long-Term
Equity Returns. The Journal of Finance, 66(2), 635-653.

Bondt, W. F., \& Thaler, R. (1985). Does the stock market overreact?. The Journal of finance, $40(3)$, 793-805.

Edelen, R. M., Ince, O. S., \& Kadlec, G. B. (2016). Institutional investors and stock return anomalies. Journal of Financial Economics, 119(3), 472-488.

Falkenstein, E. G. (1996). Preferences for stock characteristics as revealed by mutual fund portfolio holdings. The Journal of Finance, 51(1), 111-135.

Fama, E. F., \& French, K. R. (1993). Common risk factors in the returns on stocks and bonds. Journal of financial economics, 33(1), 3-56.

Fama, E. F., \& French, K. R. (2010). Luck versus skill in the cross-section of mutual fund returns. The journal of finance, 65(5), 1915-1947.

Frazzini, A., \& Lamont, O. A. (2008). Dumb money: Mutual fund flows and the cross-section of stock returns. Journal of Financial Economics, 88(2), 299-322.

Friend, I., Blume, M., \& Crockett, J. (1970). Mutual funds and other institutional investors: a new perspective. McGraw-Hill Companies.

Froot, K. A., Scharfstein, D. S., \& Stein, J. C. (1992). Herd on the street: Informational inefficiencies in a market with short-term speculation. The Journal of Finance, 47(4), 14611484.

Grinblatt, M., Titman, S., \& Wermers, R. (1995). Momentum investment strategies, portfolio performance, and herding: A study of mutual fund behavior. The American economic review, 1088-1105.

Hirshleifer, D., Subrahmanyam, A., \& Titman, S. (1994). Security analysis and trading patterns 
when some investors receive information before others. The Journal of Finance, 49(5), 1665-1698.

Huang, T. C., Wu, C. C., \& Lin, B. H. (2016). Institutional herding and risk-return relationship. Journal of Business Research, 69(6), 2073-2080.

Hwang, S., \& Salmon, M. H. (2001). A new measure of herding and empirical evidence.

Jiao, Y., \& Ye, P. (2014). Mutual fund herding in response to hedge fund herding and the impacts on stock prices. Journal of Banking \& Finance, 49, 131-148.

Klemkosky, R. C. (1977). The impact and efficiency of institutional net trading imbalances. The Journal of Finance, 32(1), 79-86.

Kraus, A., \& Stoll, H. R. (1972). Parallel trading by institutional investors. Journal of Financial and Quantitative Analysis, 7(05), 2107-2138.

Kutchukian, E. (2010). O efeito manada nos fundos de investimento no Brasil: um teste em finanças comportamentais. Masters Dissertation, Getúlio Vargas Foundation, São Paulo, SP, Brazil.

Lakonishok, J., Shleifer, A., \& Vishny, R. W. (1992). The impact of institutional trading on stock prices. Journal of financial economics, 32(1), 23-43.

Lobao, J., \& Serra, A. P. (2007). Herding behaviour: Evidence from Portuguese mutual funds. In Diversification and portfolio management of mutual funds (pp. 167-197). Palgrave Macmillan UK.

Sanches, M. V. (2013). Comportamento de manada em direção ao indice de mercado: evidências no mercado brasileiro de açóes. Doctoral Thesis, São Paulo University, São Paulo, SP, Brazil.

Scharfstein, D. S., \& Stein, J. C. (1990). Herd behavior and investment. The American Economic Review, 465-479.

Sias, R. W. (2004). Institutional herding. Review of financial studies, 17(1), 165-206.

Tariki, F. R. (2014). Evidência do efeito manada em fundos de renda variável na indústria de fundos brasileira. Masters Dissertation, Getúlio Vargas Foundation, São Paulo, SP, Brazil.

Wermers, R. (1999). Mutual fund herding and the impact on stock prices. The Journal of Finance, 54(2), 581-622.

Wermers, R. (1997). Momentum investment strategies of mutual funds, performance persistence, and survivorship bias. University of Colorado. Working Paper.

Zeng, Y. (2016). Institutional investors: Arbitrageurs or rational trend chasers. International Review of Financial Analysis, 45, 240-262. 


\section{About the Authors:}

1. Elaine Borges, PhD in Administration, University of São Paulo, Faculty of Economics, Administration, Accounting and Actuarial Sciences. São Paulo, Brazil. E-mail: profelaineborges@gmail.com

ORCID

iD 0000-0001-9123-1602

2. Roy Martelanc, Doctor of Business Administration, University of São Paulo, Faculty of Economics, Administration, Accounting and Actuarial Sciences. São Paulo, Brazil. E-mail: rmartela@usp.br

ORCID

iD 0000-0003-3220-8730

Tese de Doutorado - Universidade de São Paulo

Faculdade de Economia, Administração, Contabilidade e Atuária

Título: O Impacto do Investidor Institucional no Preço das Açóes, Ano de obtenção: 2017.

Orientador: Roy Martelanc.

Bolsista do(a): Coordenação de Aperfeiçoamento de Pessoal de Nível Superior, CAPES, Brasil

\section{Contribution of each author}

\begin{tabular}{lcc}
\hline Contribution & Elaine Borges & Roy Martelanc \\
\hline 1. Definition of research problem & $\sqrt{ }$ & $\sqrt{ }$ \\
2. Development of hypotheses or research questions (empirical studies) & $\sqrt{ }$ & $\sqrt{ }$ \\
3. Development of theoretical propositions (theoretical Work) & $\sqrt{ }$ \\
4. Theoretical foundation/ Literature review & $\sqrt{ }$ \\
5. Definition of methodological procedures & $\sqrt{ }$ \\
6. Data collection & $\sqrt{ }$ \\
7. Statistical analysis & $\sqrt{ }$ \\
8. Analysis and interpretation of data & $\sqrt{ }$ \\
9. Critical revision of the manuscript & $\sqrt{ }$ \\
10. Manuscript Writing & $\sqrt{ }$ \\
11. Other (please specify which) & \\
\hline
\end{tabular}

